\title{
Web Maps for Risk Communication: Assessing Availability of Online Disaster Maps on Government Web Sites in Indonesia
}

\author{
Kartika Puspita Sari $^{\text {a, }}$ *, Hidehiko Kanegae ${ }^{\text {b }}$ \\ ${ }^{a}$ Graduate School of Policy Science - Ritsumeikan University, ps0204fr@ed.ritsumei.ac.jp \\ ${ }^{b}$ Graduate School of Policy Science - Ritsumeikan University, hkanegae@sps.ritsumei.ac.jp \\ * Corresponding author
}

Keywords: Web maps, Risk communication, Disasters, Government Web sites, Availability

\begin{abstract}
:
The integration of Web 2.0 technologies into e-government applications and the adoption of Web GIS have revolutionized government Web sites into a sharing, socializing, and collaborating medium of government with its citizens. Many government Web sites adopted Web GIS and deliver various information to the public via web maps. Recently, web maps are not only limited to delivering local information on zoning, land use plan, property assessment, or demographic visualization. These digital cartographies are now also served as a two-way interactive communication medium and a decision support tool. In a context of disaster, web maps have been progressively utilized in emergency response, primarily to support collaboration among different agencies or jurisdictions. Online maps are also functioned as a risk communication medium as it can help to visualize hazards to increase one's awareness of risks of natural hazards. Myriad spatial information about disasters are now available on the Internet, starts from a static type of maps or single-view maps with non-modifiable displays, up to interactive mapping that offers the user to select preferred features to display. Interestingly, many offer a simple user interface that requires no specialized knowledge to use, and that is accessible anywhere as long as the Internet is available. This study aims to identify the availability of disaster web maps provided by governments in each level (national, provincial, and municipal level) and to assess the features of this type of spatial information more detailed by using selected regions and municipalities. As our concern is on developing nations, we select Indonesia as an area of study since it could represent a country with fast-emerging Internet engaged citizens and also is characterized by a frequent disaster event and severity of catastrophic events. By making use of keyword searches and observing carefully, we search the maps primarily from official government Web sites ( 1 national site, 34 provincial sites, and 497 municipal sites are available) and their disaster management agency's Web sites ( 2 national level sites, 24 provincial level sites, and 147 municipal level sites are available). We also collect data from the government's geo-portals or Web GIS platforms, both those that have already linked to the National Spatial Data Infrastructure (Ina-geoportal) and have not. We perform comparative content analysis and compare features, types of information displayed (hazards or damage assessment or report), and performances of available maps obtained in each level of the government Web site. Findings demonstrate that at the national level there are more wideranging features of disaster web maps, while at the provincial and municipal level this situation is limited to several regions, particularly those with historical records of high frequency or severity of disasters. In general, this study reveals that dissemination of disaster-themed web mapping in Indonesia on government Web sites is still limited to the static type ones.
\end{abstract}

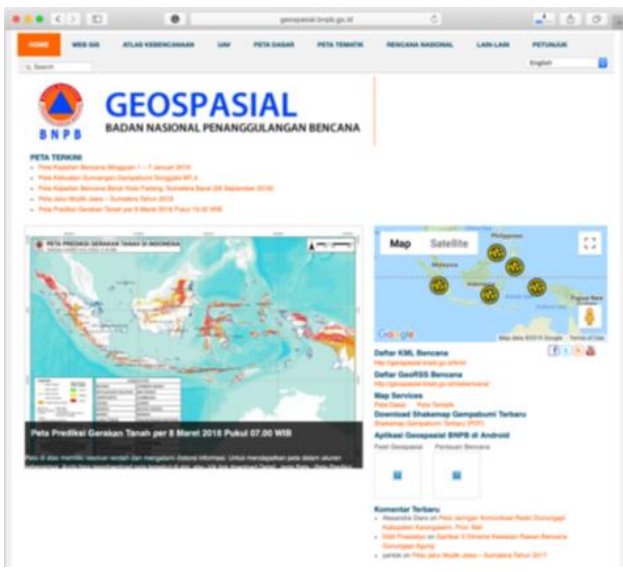

(a) http://geospasial.bnpb.go.id

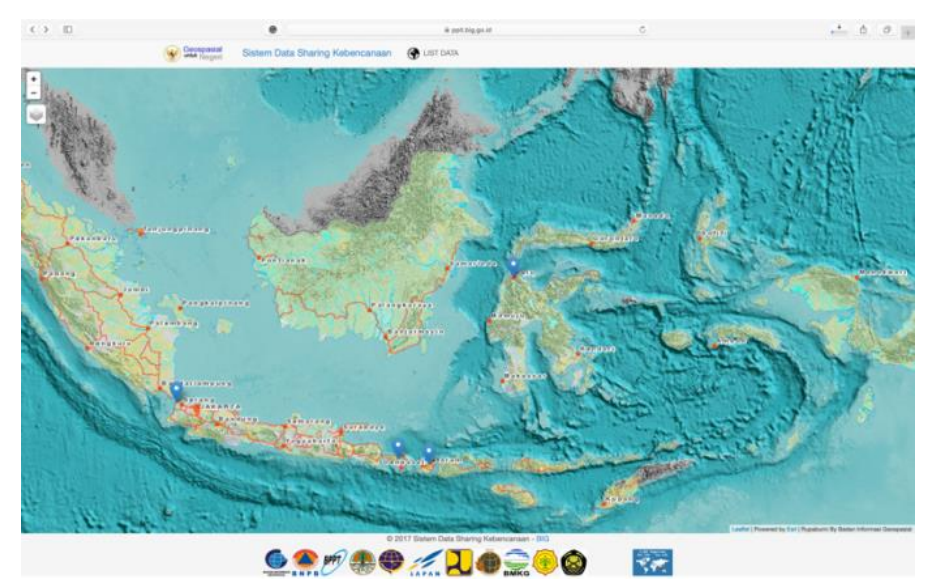

(b) https://ppit.big.go.id/databencana/

Figure 1. Spatial information about disasters provided by national government ((a): National Disaster Management Agency Web site and (b): National Geoportal (National Spatial Data Infrastructure). 


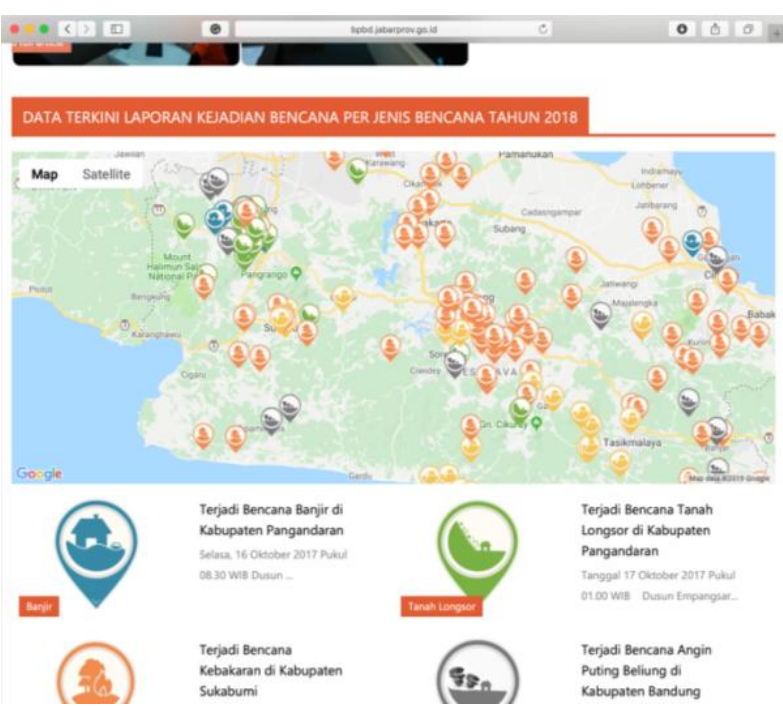

(a) http://www.bpbd.jabarprov.go.id

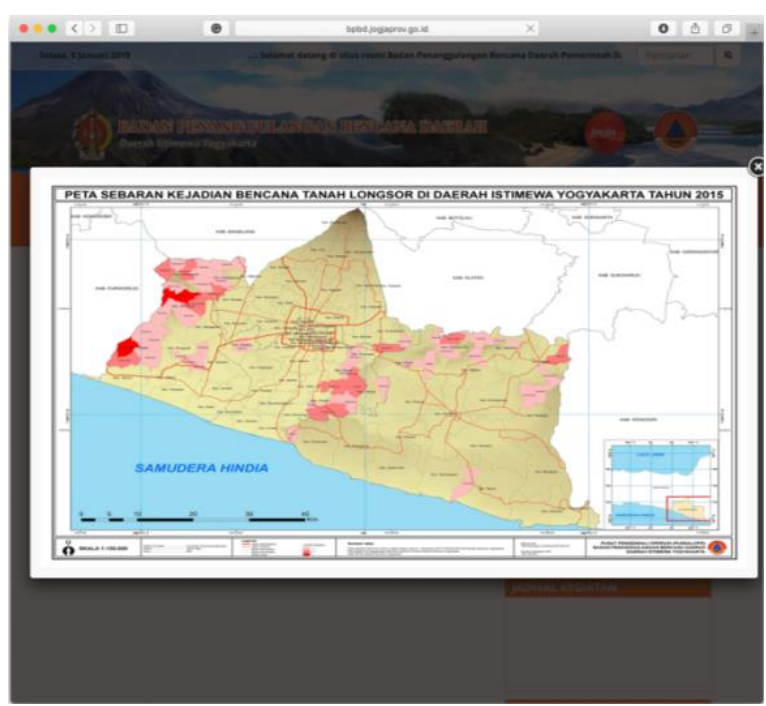

(b) http://bpbd.jogjaprov.go.id/

Figure 2. Disaster maps disseminated on provincial government Web sites.

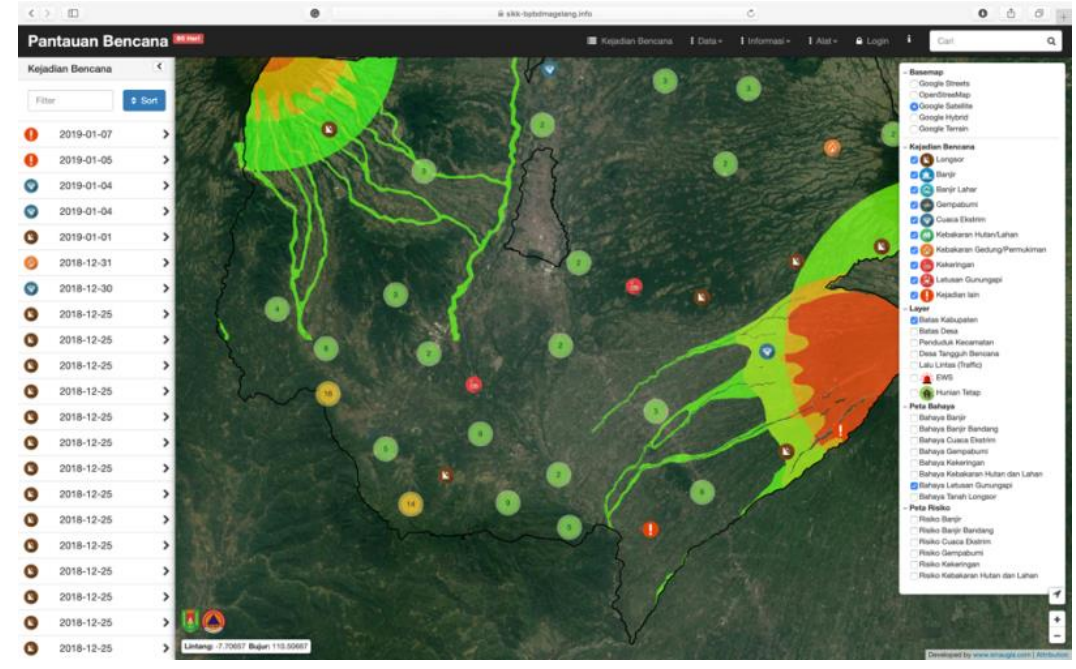

(a) https://sikk-bpbdmagelang.info

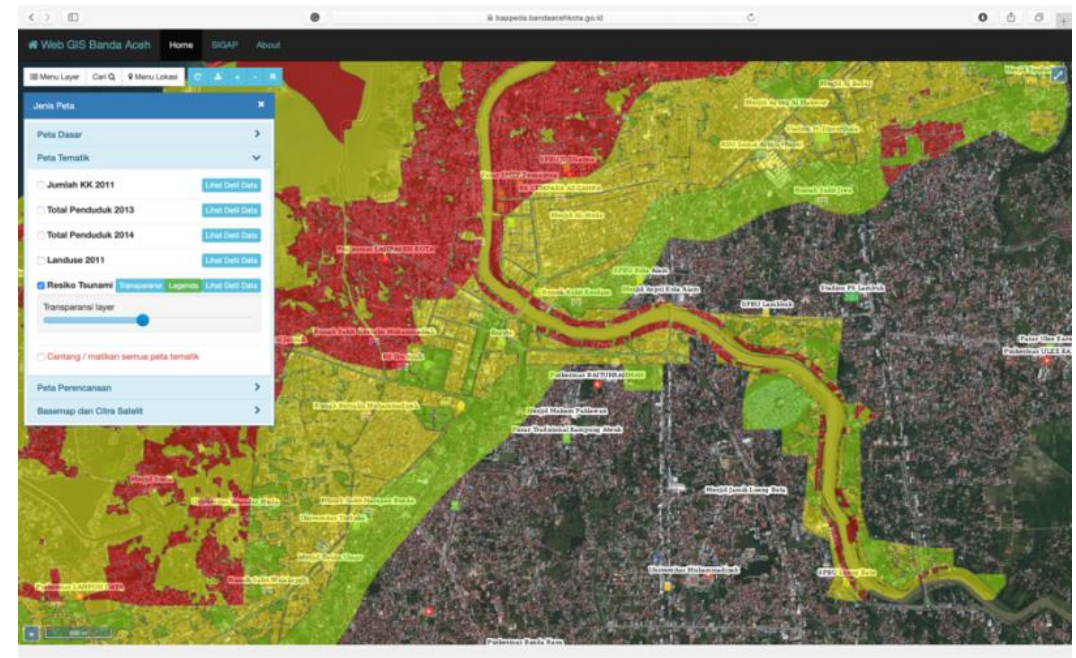

(b) https://bappeda.bandaacehkota.go.id/webgis/\#/

Figure 3. Interactive disaster web maps provided by municipal level government. 